\title{
Urban Design Study of Resilient City in Greater Bay Area ${ }^{1}$
}

Author 1 Peijun LU, South China University of Technology; China

Author 2 Yimin SUN, South China University of Technology, State Key Laboratory of Subtropical Building Science; China

Author 3 Bilin CHEN, South China University of Technology; China

Author 4 Sheng XIA, South China University of Technology; China

\section{Abstract}

With the increasing climate change, the contradiction between the vulnerable natural conditions and rapid urbanization in Guangdong-Hong Kong-Macao Greater Bay Area becomes much more prominent. Urban security is threatened by various severe natural disasters, such as rising sea level, storm surges, and intensified floods, etc. To solve this problem, based on the theory of resilient city, this paper develops three resilient urban design principles: 1) integrated city principle; 2) adaptive technology principle; 3) flexible design principle, and build a research-designfeedback loop pattern. In the research and prediction stage, we quantitatively calculate the influence of natural disasters that may happen in the future in the Greater Bay Area and map the disaster influence in the natural basement layer, urban infrastructure network layer and urban settlement layer by Geographic Information System(GIS) through scenario stimulation. Based on this, the most severely affected areas in the future will be defined as key design areas. In the urban design stage, we focus on one of the key design areas - Pazhou and stimulate multiple scenarios to assess the urban resilient risk. We propose different integrated urban design strategies to balance the urban development and risk, select the adaptive hydraulic engineering technology to realize a more sustainable green infrastructure and build a flexible development framework to face the future uncertainty. In the evaluation and feedback stage, we develop a time series model of heavy rainfall to evaluate urban resilience in different design and quantify the impact of natural disasters through a set of urban resilience indicators in various layers, in order to pick up more resilient design to optimize. The practice experience shows that the resilient city is a long-term process, which requires an interdisciplinary cooperation mode, among research, design and feedback and a great management and control platform and a multi-objective evaluation index system so as to achieve real-time monitoring, regular evaluation, and dynamic control. This study attempts to make up for the lack of resilience city research in planning and design practice, to provide practical experience for the next stage of urban building.

\section{Keywords}

Resilience, Greater Bay Area, Planning and Building, Design and feedback

1 International Cooperation and Exchanges National Natural Science Foundation of China (Cooperation Project of China, Netherlands and Britain) : Adaptive Urban Transformation (AUT) - Territorial governance, spatial strategy and urban landscape dynamics for a more resilient Pearl River Delta (No:51761135025) ; 


\section{Background: Urban Resilience in Greater Bay Area facing severe challenges}

The Pearl River is the second largest river in terms of stream flow. Guangdong-Hong KongMacao Greater Bay is located in the complex area in the Pearl River which is formed by the three main river Xijiang, Beijing, and Dongjiang (Liang Xiong, 2019). The Greater Bay is one of the most quickly developing region in the field of urban expansion in the world for the past four decades. The built-up area emerged at an average speed of $122.25 \mathrm{~km} 2 /$ year between 2000 and 2016 (Yang Zhiwei, 2018), while the GDP increased over 1000 folds from 1980 to 2016 and the population grow explosively from 20.1 million to 61.46 million between 1982 and 2016. However, on the one hand, the Greater Bay Area belongs to the estuary alluvial plain, which located in low altitude and sea-land boundary that determined its own ecological vulnerability (Meyer \& Nijhuis, 2014). On the other hand, the frequent natural disasters led by climate change, rapid urban expansion and an increasing number of the population have caused serious damage to the ecological environment of Greater Bay Area, weakening the urban resilience to natural disasters and shortening the life cycle of sustainable development (Dai Wei, 2019). According to historical statistics, from Qin Dynasty to Qing Dynasty (over 2100 years), more than 100 floods have occurred in the Guangzhou section of the Pearl River, with an average of 20 years per flood (Qingzhou, 2009). Since the $20^{\text {th }}$ century, Since the 20th century, there have been two major floods causing more than 100,000 deaths and injuries (Qingzhou, 2002). Therefore, as the Greater Bay Area has risen to be a national strategy, it is more urgent to improve the urban resilience by urban study, plan, and design, and propose a systematic framework to make resilience cities.

Both foreign and domestic scholars have achieved preliminary results on the resilience city in the Greater Bay Area. Liang Xiong and Steffen Nijhuis mapped the landscape formation, water infrastructure network and urbanization in the Pearl River District from 4000 BC to 2015 AD, to show the different dynamics of the delta and understand the interaction among the tangible and intangible components of the delta system (Liang Xiong, 2019). Based on the study of the post-disaster spatial resilience planning and design in Delta city such as Rotterdam in the Netherlands, New York and New Orleans in the United States, Dai Wei had built a systematic spatial plan framework for Delta city and try to apply into urban design in Pazhou West District (Dai Wei, 2019; Dai Wei, 2018). South China University of Technology has carried out a series of historical studies on the theme of the water system. Liu Wei had studied on the urban canal-system of ancient Guangzhou (Wei, 2015). Li Jiahao research on evolution and dynamic mechanism of the water system in Shunde, Foshan.

Next, in the first part, this study firstly proposes three resilient urban design principles: 1 ) integrated city principle; 2) adaptive technology principle; 3) flexible design principle, and presents a research-design-feedback loop pattern adapted to the current situation of the Greater Bay Area. In the second part, this study evaluates the comprehensive influence of the natural disaster may happen in the future in the Greater Bay Area by scenario analysis and define the key design area. In the third part, this study takes Pazhou as an example to apply the resilience urban design. On the basis of the assessment on multi-scenario risk, the design propose different development model to balance the benefit between the urban development and urban risk, apply the mix land use principle to deal with the uncertainty in the future and pick up a suitable, adaptive and ecological engineering technology to achieve a public, sustainable infrastructure. In the fourth part, this study builds a time series model of 
heavy rainfall to assess the urban resilience of different design. In the last part, we point out the limitation of the evaluation system and discuss the tendency in the future that urban planning and design will toward integration and interdisciplinary, so we suggest to build a management platform to control the implementation.

\section{Strategy: Resilient Urban Design Principle}

Resilient cities are defined as the ability of the urban system to digest and absorb external disturbances, maintain the original structure and the key functions (Resilience Alliance, 2007). Its basic structure can be summarized into four aspects: economy, engineering, environment and society (Chen Li, 2017). Therefore, based on the Layer-cake model by lan McHarg (IL McHarg, 1969), Dutch scholars developed the vertical stratification research methods in the 1980s. Meyer studied the Delta City resilient evolution law of urban system and decomposed the evolution of urban system into three layers based on spatial flow: 1) the first layer is the natural basement, mainly dealing with the natural environment, including the agriculture system, water system, and ecological system; 2) The second layer is the urban infrastructure network, which consists of subsystems such as transportation system, water conservancy system and municipal engineering system. 3) The third layer is the urban settlement, which mainly reflects the social and economic status of the city. This layer is composed of some subsystems such as land use system and industrial development system. Mayer's research team also used Geographic Information System (GIS) to mapping the development of different layers of Delta Cities around the world, revealing the evolution rate change of different layers and the restriction relationship between different layers (Meyer \& Nijhuis, 2014). On the basis of this research, Dai Wei proposed the delta spatial planning principle based on the resilience system, emphasizing that the planning goal of improving urban resilience is based on the inherent evolution law of the urban system, the collaborative planning as the means and scenario stimulation as the planning guidance. Through case analysis (Dai Wei, 2019).

In view of the current situation of urban development in the Greater Bay Area, the author proposes three resilient urban design principle:

1) Integrated city principle: Taking the phenomenon about "individually in the process of construction" into account, the author thinks that the city should be considered as an entirety and the solution of the urban problem should be considered as a comprehensive and interdisciplinary process.

2) Adaptive technology principle: In view of the current situation that engineering technology tends to be a large-scale transformation of nature. The author believes that we should deepen the grasp of the engineering technology and emphasize to adopt the appropriate, ecological and sustainable engineering techniques to achieve a high-quality and high-resilience green infrastructure system.

3) Flexible design principle: in order to address the uncertainty of policy and the variability of natural disasters in the future. The author emphasizes the method for responding to dynamic demand, using the scenario simulation to explore the flexibility and adaptability of land use and building the dynamic management and control system to implement. 
Based on the above principles, the author develops a research-design-feedback loop pattern for the actual situation in the Greater Bay Area. Starting from the macroscopic natural basement research, planning and designing the urban infrastructure network to guide the urban social and economic development.

1) Research Forecasting: Studying other professional research results and similar cases, some of the most probable and most demanding scenarios in the future are derived as planning simulation scenarios to increase the proactive prevention strategy for uncertainty.

2) Systematical Design: Focus on the scenarios analysis result, identify the key to constrain the future development, propose the urban design integrate development framework to determine the spatial layout, rationally select the land use model to cope with the uncertainty of future development, and select appropriate engineering techniques based on construction needs.

3) Evaluation Feedback: It belongs to a part of design control. Builds a quantitative indicator system to correct the design direction and implementation direction through feedback. When there is a large deviation between the evaluation result and the expected goal, feedback is given in various forms such as qualitative, quantitative, grading and shaping.

\section{Research Forecasting: Scenario Analysis Delineating Key Design Areas}

Greater Bay Area is selected as the macro-level scenario simulation. As shown in Figure 1, it is the urban agglomeration of Guangzhou(GZ), Shenzhen(SZ), Foshan(FS), Dongguan(DG), Zhongshan(ZS), Zhuhai(ZH), Huizhou(HZ), Jiangmen(JM), Zhaoging(ZQ), and two Special Administrative Regions of Hong Kong(HK) and Macao(MC), which is planned to be constructed as a world-class urban agglomeration and the forth Bay Area in the word. 


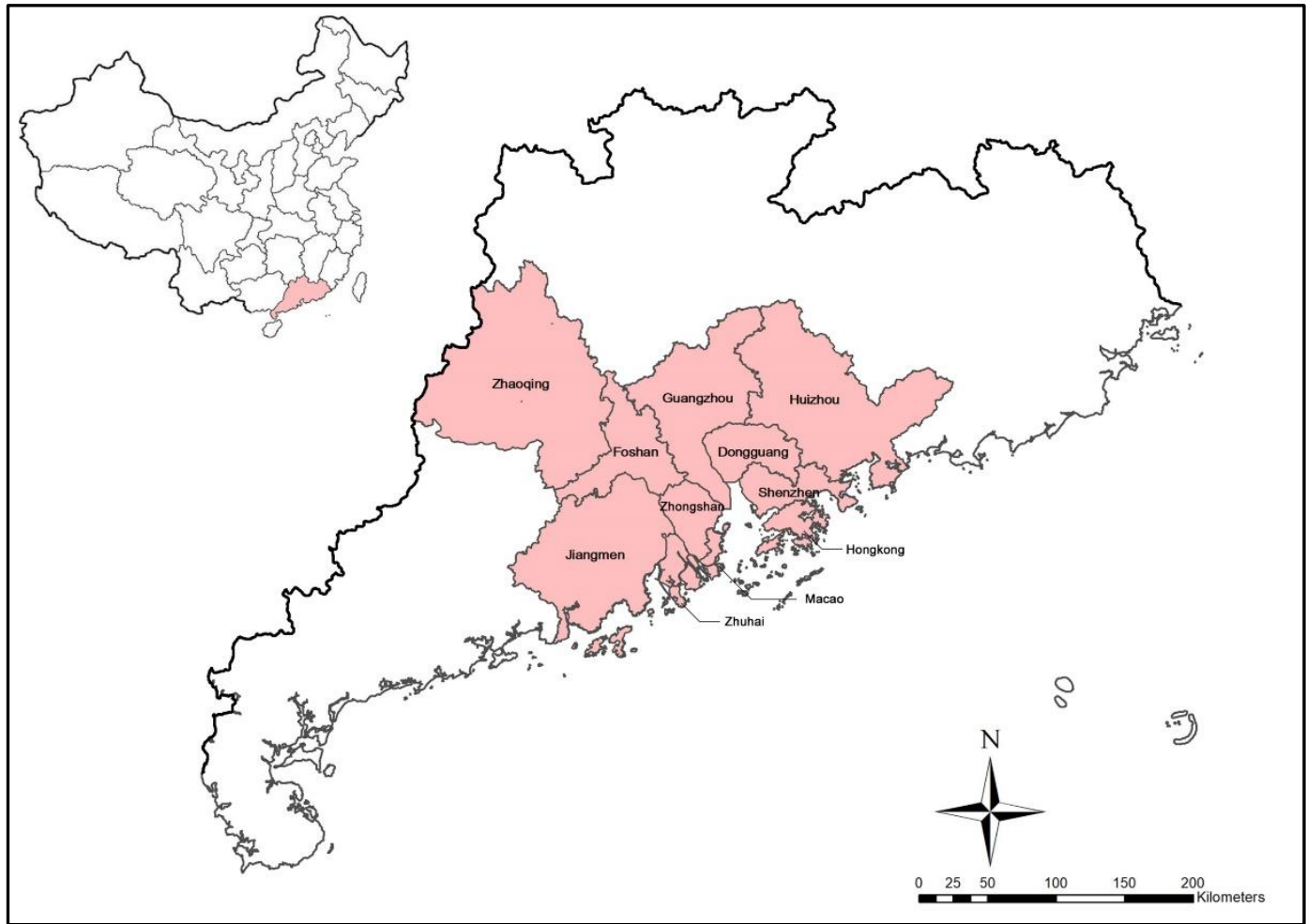

Figure 1 regional scale (Source: by author)

The research data includes the 2017 urban Land-Use and Land-Cover Change (grid resolution of $30 \mathrm{~m}$ ) describing the natural basement of the Greater Bay Area, and the urban road space distribution data and urban elevation data (DEM) demonstrating the urban infrastructure network. All the data is provided by the Resource and Environment Data Cloud Platform (http://www.resdc.cn/Default.aspx). In addition, the economic and population data of the street units of the Greater Bay Area are mainly from the statistical yearbooks of each city (Table 1). The research data also includes boundary vector data for the street (town) unit of Greater Bay Area, which is obtained from the open source map data platform OpenStreetMap (https://planet.openstreetmap.org/). In order to ensure the unification of the data, the study uses the ArcGIS platform to convert all data into a horizontal Mercator projection.

\begin{tabular}{|c|c|c|c|c|c|}
\hline City & $\begin{array}{l}\text { Area } \\
\left(\mathrm{km}^{2}\right)\end{array}$ & $\begin{array}{l}\text { Population } \\
\text { (million) }\end{array}$ & $\begin{array}{c}\text { Population } \\
\text { Density } \\
\text { (persons } / \mathrm{km}^{2} \text { ) }\end{array}$ & $\begin{array}{c}\text { GDP } \\
\text { (billion dollar) }\end{array}$ & $\begin{array}{c}\text { GDP per km² } \\
\text { (million } \\
\text { dollar } / \mathrm{km}^{2} \text { ) }\end{array}$ \\
\hline $\mathrm{GZ}$ & 7436 & 14.4984 & 1949.76 & 321.26 & 43.20 \\
\hline $\mathrm{SZ}$ & 2020 & 12.5283 & 6202.28 & 336.00 & 166.34 \\
\hline $\mathrm{ZS}$ & 1770 & 3.26 & 1841.81 & 51.25 & 28.95 \\
\hline DG & 2512 & 8.3425 & 3321.06 & 113.28 & 45.09 \\
\hline FS & 3875 & 7.6567 & 1975.92 & 140.41 & 36.24 \\
\hline $\mathrm{ZH}$ & 1696 & 1.7654 & 1040.92 & 39.97 & 23.57 \\
\hline $\mathrm{ZQ}$ & 15006 & 4.1154 & 274.25 & 31.52 & 2.10 \\
\hline $\mathrm{JM}$ & 9554 & 4.5617 & 477.46 & 40.19 & 4.21 \\
\hline
\end{tabular}




$\begin{array}{rrrrrr}\text { HZ } & 11159 & 4.777 & 428.09 & 57.23 & 5.13 \\ \mathrm{HK} & 1104 & 7.392 & 6695.65 & 327.08 & 296.27 \\ \mathrm{MC} & 29 & 0.648 & 22191.78 & 303.93 & 10408.67\end{array}$

Table 1 Population and GDP data of each city in Pearl River Delta (Source: statistical yearbooks of each city)

\subsection{Assessment of the Impact of Disasters on the Natural Environment and Urban Construction on a Macro Scale}

Considering that storm surges and sea level rise will become one of the main natural disasters in Greater Bay Area, the study adopts a spatial overlaying method to extract land data of 3 layers of natural basement, urban infrastructure network and urban settlement, which are affected by storm surges under different scenarios. Among them, the estimation of sea level rise is based on the research results of Li Guangsheng research group specifically for sea level change in the Pearl River Delta: in consideration of sea level rise and storm surge superposition, the optimal condition of the Pearl River sea level elevation in 2050 is estimated to be $3.3 \mathrm{~m}$, and the worst situation is estimated to be $4.5 \mathrm{~m}$ (Li Guosheng, 2013).

Therefore, without considering the protection capability of the seawall, supported by GIS spatial analysis technology and based on the DEM data of the Pearl River Delta region, we first analyze the various types of land areas that are submerged at different heights of sea level rise, and then draw the impact of sea level rise superimposed storm surges on the natural basement and urban infrastructure network in Greater Bay Area under different scenarios in 2050, and point out the possible impacts of farmland, green space, constructed land and roads in different cities. Then we estimate in detail the impact of sea level rise superimposed storm surges on street-scale urban construction.

Figure 2 illustrated the impact of sea level rise on the natural environment and urban construction under different scenarios. With the increase of sea level and storm surge water level, the flooded area ranks first of farmlands and constructed lands in the Greater Bay Area, which is followed by the water areas and the tidal flats around it, while the flooded area of grasslands and woodlands are growing very little. Specifically, under the best estimate of sea level rise and storm surge water increase in 2050, the total area of submerged farmland is $734.01 \mathrm{~km}^{2}$, and the total constructed land area is $835.28 \mathrm{~km}^{2}$, accounting for $36.88 \%$ and $41.97 \%$ of the total area inundated, respectively. Under the worst estimate in 2050 , the total area of submerged farmland is $1054.12 \mathrm{~km}^{2}$, and the total constructed land area is 1054.12 $\mathrm{km}^{2}$, with respectively $36.99 \%$ and $42.30 \%$ of the total inundated area. 


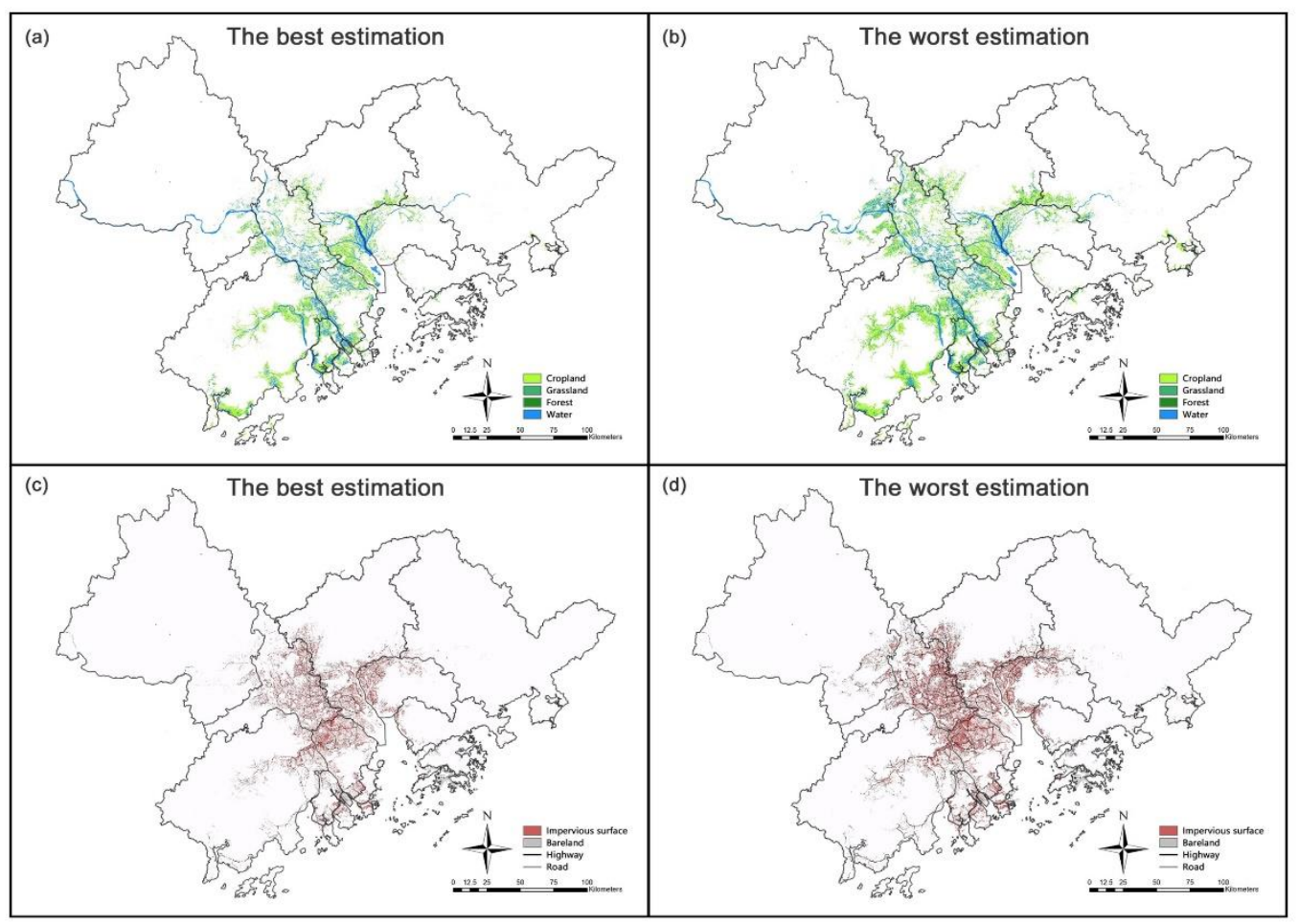

Figure 2 Different estimation of rising sea level on the natural environment and urban construction (Source: by author)

Specific to each city (Table 2), in the estimation of the impact of sea level rise and superimposed storm surges under different scenarios from the perspective of the natural system, Foshan has the greatest impact, followed by Zhongshan and Zhuhai. Specifically, under the optimal estimation scenario, Foshan is flooded with $15.30 \%$ of farmland and $19.03 \%$ of grassland, and under the worst one, it is flooded with $25.08 \%$ of farmland and $28.70 \%$ of grassland. From the perspective of the urban system, Zhongshan and Foshan are seriously affected, and Zhuhai and Jiangmen go next. That is, the impact on the west bank of the Pearl River was greater than that on the east coast.

\begin{tabular}{crrrrrrrr}
\hline \multirow{2}{*}{ city } & \multicolumn{2}{c}{ Cropland } & \multicolumn{2}{c}{ Grassland } & \multicolumn{2}{c}{ Construction Land } & \multicolumn{2}{c}{ Urban Network } \\
& \multicolumn{1}{c}{ Best } & Worst & \multicolumn{1}{c}{ Best } & Worst & Best & Worst & Best & Worst \\
\hline GZ & $5.75 \%$ & $9.39 \%$ & $4.90 \%$ & $8.26 \%$ & $8.56 \%$ & $14.55 \%$ & $7.88 \%$ & $13.53 \%$ \\
SZ & $1.66 \%$ & $3.06 \%$ & $1.57 \%$ & $2.78 \%$ & $3.37 \%$ & $6.22 \%$ & $3.44 \%$ & $6.68 \%$ \\
ZS & $11.01 \%$ & $14.34 \%$ & $11.17 \%$ & $14.73 \%$ & $15.87 \%$ & $22.72 \%$ & $17.33 \%$ & $25.33 \%$ \\
DG & $6.71 \%$ & $11.02 \%$ & $5.66 \%$ & $9.50 \%$ & $8.49 \%$ & $14.51 \%$ & $8.41 \%$ & $14.71 \%$ \\
FS & $15.30 \%$ & $25.08 \%$ & $19.03 \%$ & $28.70 \%$ & $19.23 \%$ & $30.46 \%$ & $19.06 \%$ & $30.49 \%$ \\
ZH & $9.68 \%$ & $13.37 \%$ & $9.48 \%$ & $12.52 \%$ & $13.30 \%$ & $19.59 \%$ & $13.09 \%$ & $19.99 \%$ \\
ZQ & $3.05 \%$ & $5.85 \%$ & $4.53 \%$ & $8.02 \%$ & $7.40 \%$ & $14.66 \%$ & $3.68 \%$ & $7.83 \%$ \\
JM & $7.99 \%$ & $11.97 \%$ & $7.92 \%$ & $11.40 \%$ & $12.02 \%$ & $19.04 \%$ & $11.29 \%$ & $18.20 \%$ \\
HZ & $2.34 \%$ & $4.72 \%$ & $1.53 \%$ & $3.14 \%$ & $3.35 \%$ & $6.45 \%$ & $2.04 \%$ & $4.31 \%$
\end{tabular}




$\begin{array}{rrrrrrrrr}\text { HK } & 4.41 \% & 8.26 \% & 2.02 \% & 3.77 \% & 6.80 \% & 13.26 \% & 3.57 \% & 7.28 \% \\ \text { MC } & 5.71 \% & 12.02 \% & 15.01 \% & 28.95 \% & 10.07 \% & 17.56 \% & 7.68 \% & 14.08 \%\end{array}$

Table 2 Different estimation of rising sea level on various land use in each city (Source: by author)

\subsection{Assessment of the Impact of Disasters on the Socio-economy on a Medium Scale}

The above research reveals the impacts of natural disasters on the layers of the natural basement and urban infrastructure network, and in this part, we consider the impact of natural disasters on the city's socio-economy. We take the area of the inundated built-up area/the area of the built-up area of the city to measure the degree of disaster in the streets, and the GDP per street unit in 2017 to measure the degree of economic development. Figure $3(a)$ and (b) illustrate the scatter plot of these two variables. At the meanwhile, we define the built-up area of more than $12 \%$ submerged (average of the best and worst estimate) and the degree of economic development exceeds $2 \times 108 \mathrm{CNY} / \mathrm{km}^{2}$ (median) as the vulnerable street unit, and we respectively display them in Figure $3 c$ and Figure $3 \mathrm{~d}$.

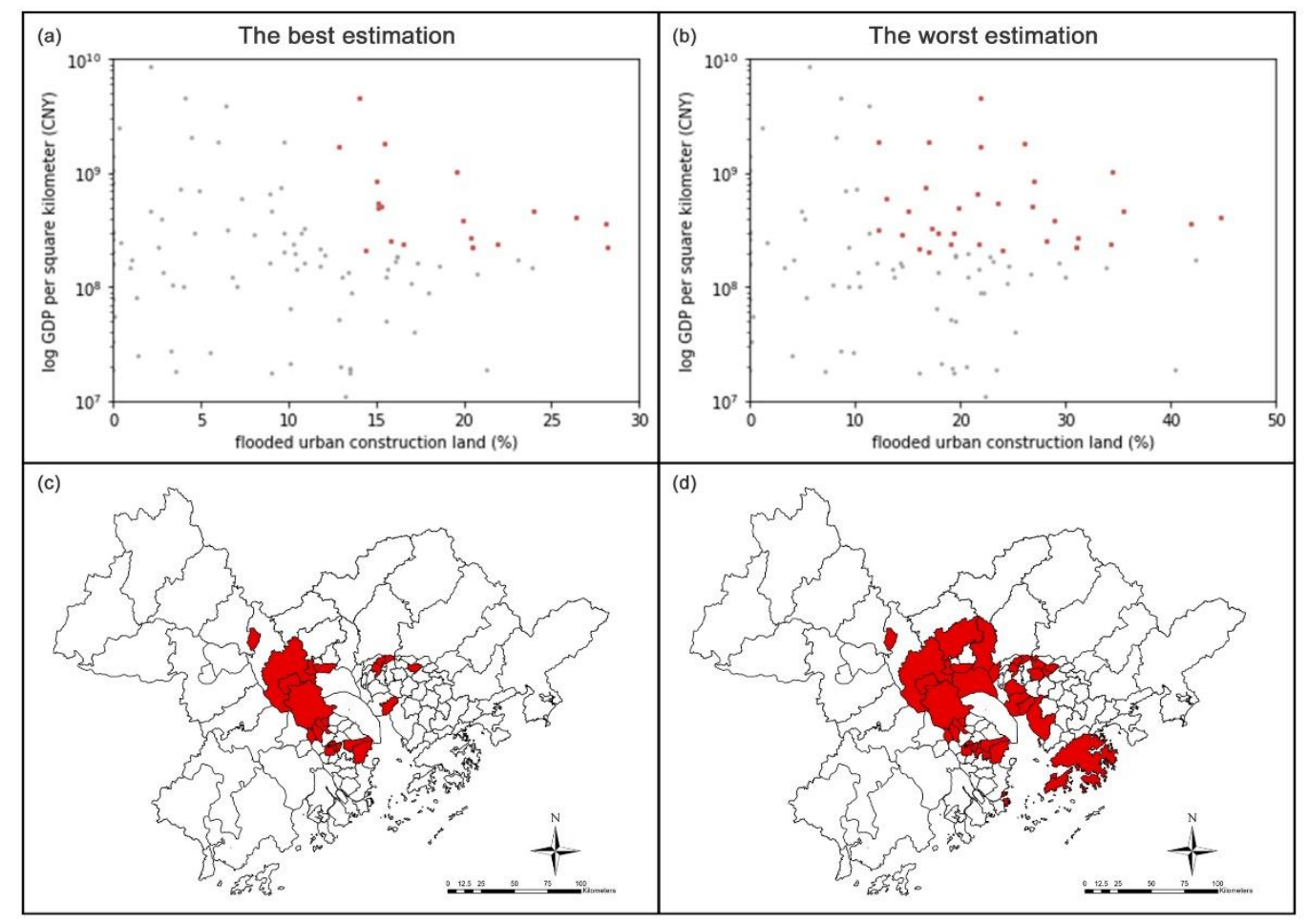

Figure 3 Different estimation of rising sea level on economics in each district (Source: by author)

The analysis shows that under the best estimation scenario, sea level rise and storm surge disasters mainly threaten the urban areas on the west bank of the Pearl River Estuary, mainly in Foshan, Guangzhou, and Zhongshan. In the worst-case scenario, the threat of disaster will spread to most of Guangzhou and Dongguan and Hong Kong on the east bank of the Pearl River.

\subsection{Delineate Key Design Areas Based on Research Results}

On the basis of the research, we use the spatial superposition method to integrate the impact of natural disasters on layers of urban infrastructure network and urban settlement, to make a resilient urban design in the key areas, key control areas and general control areas of the 
Greater Bay Area (Figure 4). Among them, the key areas refer to those where resilient urban design is urgently needed to cope with natural disasters that are likely to come, and to avoid major impacts on the city's socio-economy; the key control areas refer to the development of resilient urban planning to cope with possible natural disasters and to reduce the corresponding socio-economic losses; the general control areas refer to natural disasters that can carry out relevant tough urban studies to cope with accidents. The Central and Eastern Pazhou, which is in the key control area, is selected as the design area for further planning.

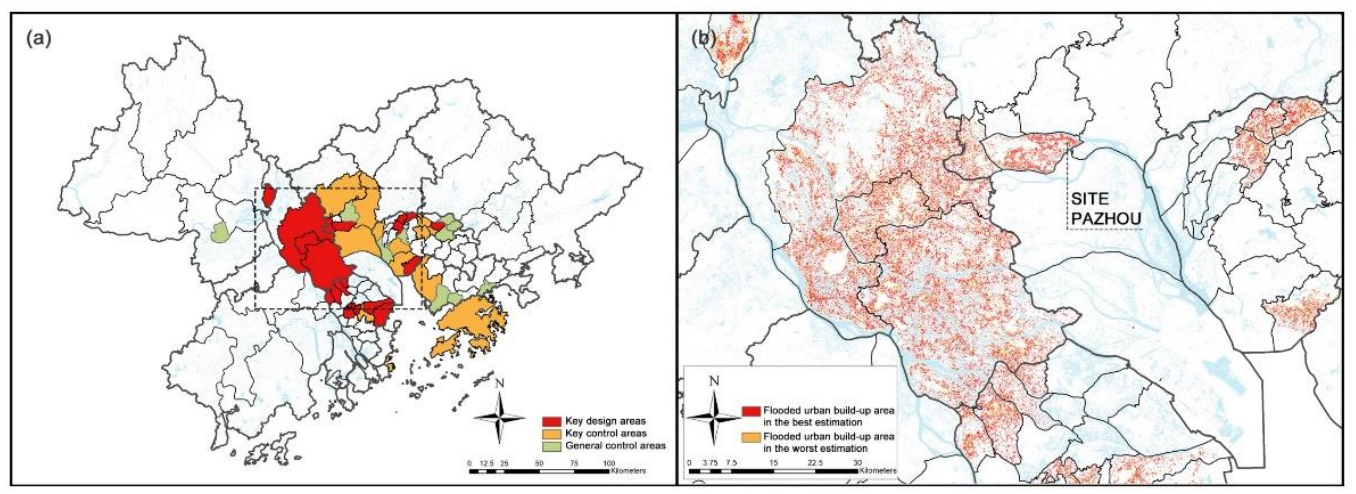

Figure 4 Key Design Areas and Pazhou (Source: by author)

\section{Systematical Design: Taking Urban Design of Central and Eastern Pazhou in Guangzhou as an Example}

Pazhou Island, Guangzhou, which is located at the junction of the eastern and the central waterways of Pearl River, has a low terrain and has been affected by typhoons and floods. In Junuary 2019, South China University of Technology (SCUT) and the University of California, Berkeley (UC-Berkeley) held a joint design workshop based on the central and eastern Pazhou, trying to explore the design methods for urban resilience in Pearl River Delta cities from the perspective of rainwater management, urban integration and compact development.

\subsection{Risk Simulation and Assessment of Pazhou Island under Multiple Scenarios}

Pazhou Island is located in Haizhu District of Guangzhou, surrounded by water, at the eastern junction of the front and rear channel of the Pearl River, and its southwest side is Huangpu Canal. It is the alluvial island, the terrain is low and the coastline is about $10 \mathrm{~km}$. At present, the elevation of the east side of the island is about $8.05 \mathrm{~m}$, and the elevation of the top of the southeast side is $6.95 \mathrm{~m}$. The average annual tidal level of the Pearl River recorded at the hydrological station (Sun Yat-sun University Station) near the east side is $8.227 \mathrm{~m}$ (2018), and that recorded at the Huangpu Station near the southwest side is $6.94 \mathrm{~m}$ (Figure 5). 


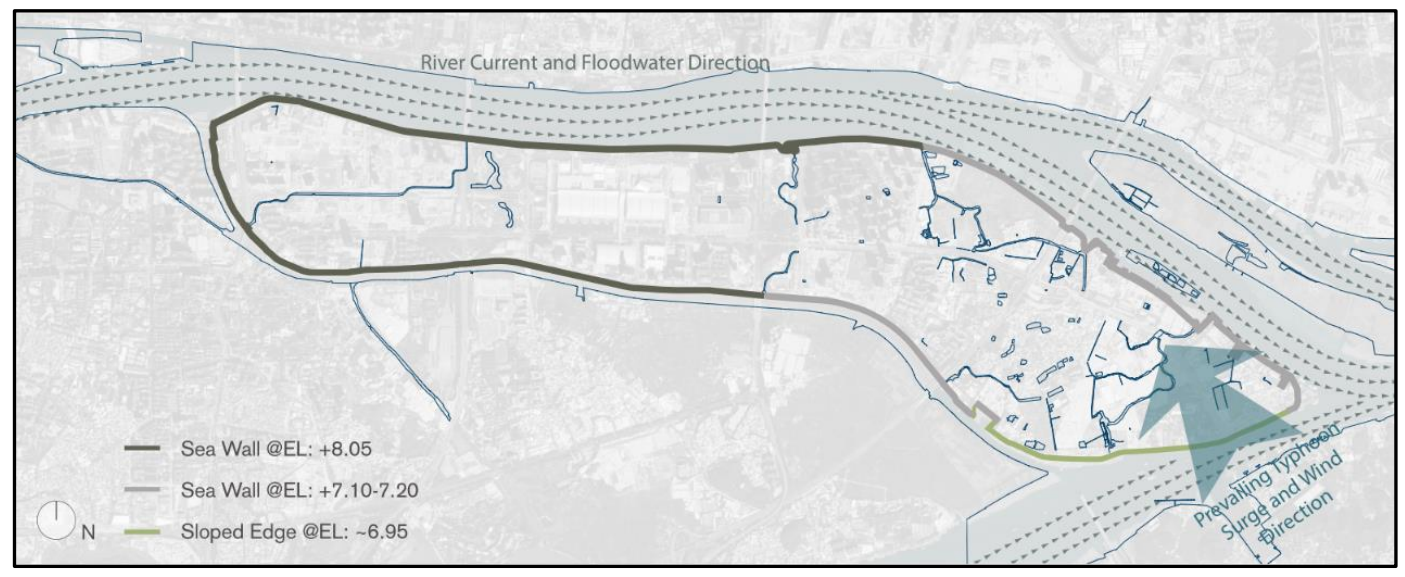

Figure 5 Hydrologic regime and water conservancy facilities (Source: UCB-SCUT workshop)

According to the universal risk of sea level rise that is likely to be faced in the Greater Bay Area, and the possible heavy rainfall and storm surges that may be caused by typhoons, in this workshop, a model for analyzing the elevation of Pazhou Island and its different heavy precipitation conditions (Figure 6) was established based on the topography of the island, without considering existing embankments, sluices and other water conservancy facilities, so as to simulate strong precipitation in $50 \mathrm{~mm}, 100 \mathrm{~mm}$ and $200 \mathrm{~mm}$ (2018 Typhoon Mangosteen).
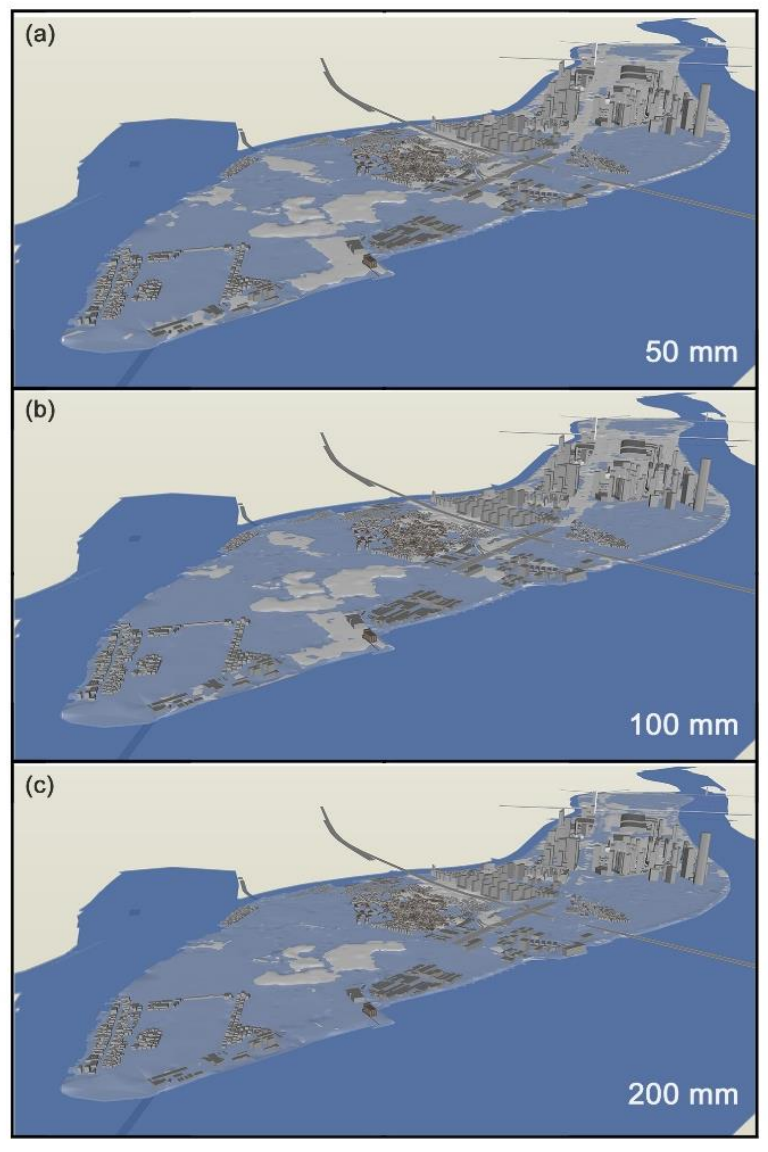

Figure 6 Flood risk scenarios (Source: UCB-SCUT workshop) 


\subsection{Overall Resilient Urban Design of Central and Eastern Pazhou}

Resilient Urban Design emphasizes the adaptability and learning ability of urban systems, to build a stable, diverse, redundant, integrated, flexible, and interconnected urban infrastructure and environment that is resistant to risks and adapts to interferences. Therefore, in view of the above risk simulation and assessment of the island, corresponding feedbacks and overall design strategies (Table 3 ) are proposed, which involve interdisciplinary aspects such as urban planning, water conservancy engineering and ecological design.

\begin{tabular}{|c|c|c|}
\hline Risk & $\begin{array}{c}\text { Related Majors and } \\
\text { Feedbacks }\end{array}$ & Specific Design Strategies \\
\hline \multirow{3}{*}{$\begin{array}{l}\text { Low- } \\
\text { lying } \\
\text { alluvial } \\
\text { island }\end{array}$} & $\begin{array}{l}\text { 1) urban planning: } \\
\text { classification of land } \\
\text { development based on the } \\
\text { terrain }\end{array}$ & $\begin{array}{l}\text { (1)Land developments of higher intensity are } \\
\text { concentrated in the highlands; } \\
\text { (2) Residential areas are arranged at high points, } \\
\text { followed by commercial, business areas and } \\
\text { major transport facilities, and finally green } \\
\text { space, farmland, and other submersible areas. }\end{array}$ \\
\hline & $\begin{array}{l}\text { 2) water conservancy } \\
\text { engineering: artificially } \\
\text { adjust the site elevation } \\
\text { according to the current } \\
\text { land shape and extreme } \\
\text { water lever }\end{array}$ & $\begin{array}{l}\text { (1)The height of parts of the embankments is } \\
\text { adjusted, which is a hardened waterfront area } \\
\text { with a narrow scale; } \\
\text { (2)The low-lying ground of residential areas are } \\
\text { to be lifted up. }\end{array}$ \\
\hline & $\begin{array}{l}\text { 3) ecological design: } \\
\text { maintain continuity in low- } \\
\text { lying habitats }\end{array}$ & $\begin{array}{l}\text { (1)The current broken water system and green } \\
\text { space are to be connected. } \\
\text { (2)Blue-green infrastructure connecting with the } \\
\text { external ones are reserved in the newly built } \\
\text { areas. }\end{array}$ \\
\hline \multirow{3}{*}{$\begin{array}{l}\text { Threats } \\
\text { of } \\
\text { storm } \\
\text { surges } \\
\text { and } \\
\text { floods }\end{array}$} & $\begin{array}{l}\text { 1) urban planning: } \\
\text { integrate land use and urban } \\
\text { transportation according to } \\
\text { base terrain }\end{array}$ & $\begin{array}{l}\text { (1)The mix-use land pattern is advocated to } \\
\text { promoted the diversity of urban space and } \\
\text { mitigate the degree of damage to the same area } \\
\text { by the risk of storms and floods; }\end{array}$ \\
\hline & & $\begin{array}{l}\text { (2) A low-carbon redundant traffic space is to be } \\
\text { established guided by public transportation, and } \\
\text { the redundancy is increased by constructing } \\
\text { pedestrian bridges on low-lying lands. }\end{array}$ \\
\hline & $\begin{array}{l}\text { 2) water conservancy } \\
\text { engineering: combine rigid } \\
\text { engineering tools with } \\
\text { resilient green infrastructure }\end{array}$ & $\begin{array}{l}\text { (1) Rigid measures are taken to reinforce dikes in } \\
\text { places which lack buffers and where is with large } \\
\text { urban construction; } \\
\text { (2)Decentralized rainwater storage design is } \\
\text { adopted in combination with green } \\
\text { infrastructure, and the existing farmland and }\end{array}$ \\
\hline
\end{tabular}


wetlands are preserved in low-lying areas to improve the adaptability to storm threats.

3) ecological design: establish natural floodplain combining low-lying lands
(1) Water squares, rain gardens, undercut or sloped green spaces are established according to different functional parts of the city;

(2) Recreational and other facilities are introduced to the natural floodplain in order to create multi-purpose space.

Table 3 Urban design strategy of Central and Eastern Pazhou (by author)

The workshop adopted two different holistic development models (Figure 7) to explore how to strike a balance between urban development and adaptability to stormwater hazards. Two different development visions were presented through design: one is to achieve intensive land development, which needs to invest in higher flood control facilities; the other one is to preserve existing farmland, vegetated areas and other open spaces, so that the constructed area and the green infrastructure system are organically integrated, and the cost of flood control is relatively low.

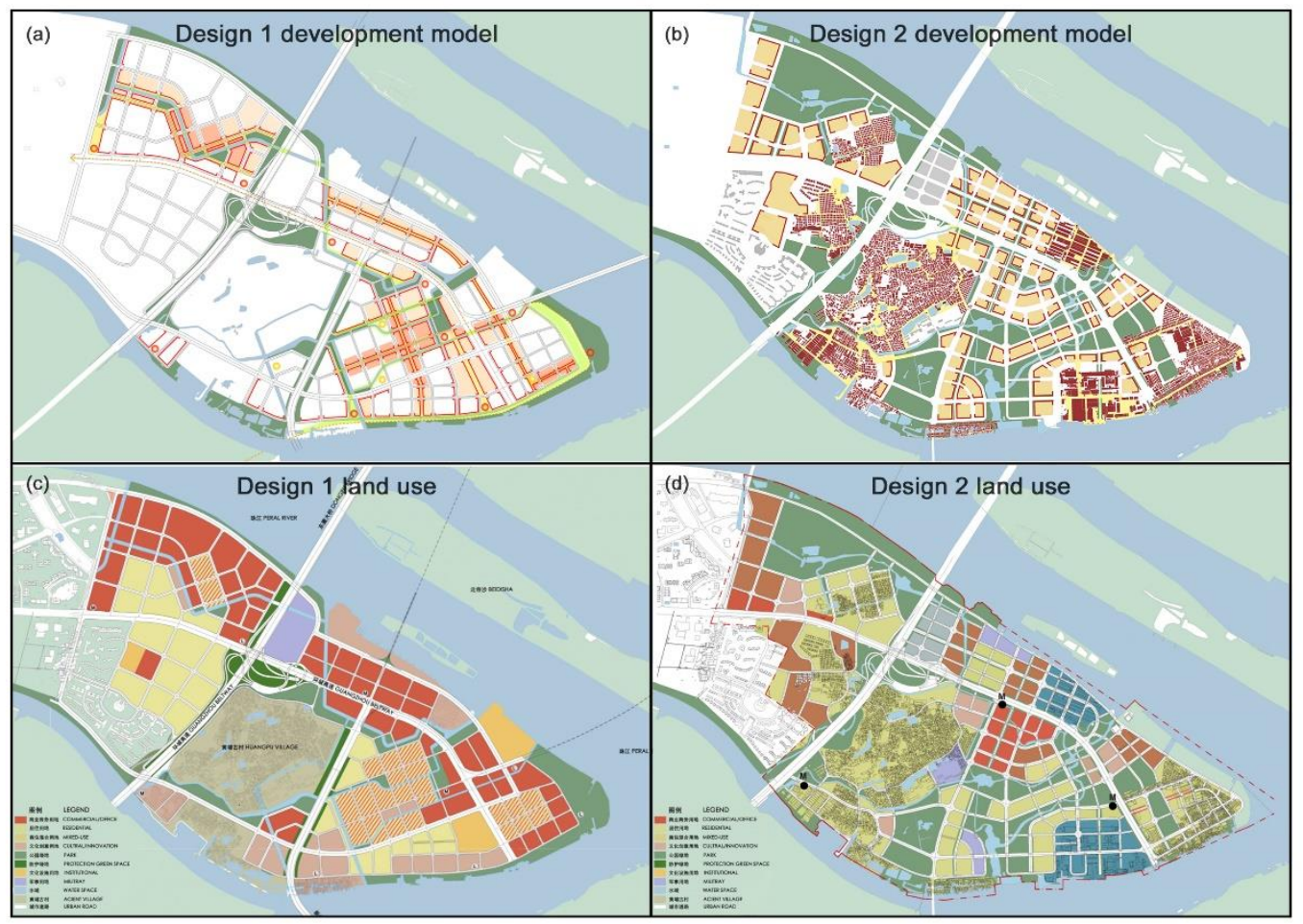

Figure 7 Development model and land use of two urban design (Source: UCB-SCUT workshop)

\subsection{Engineering Means Selection and Adaptability Evaluation}

Due to the relatively heavy rainfall in Pazhou Island, it is likely to face the threat of heavy storm surges and floods, if the rainwater is not properly stored, but only removed by engineering means. The workshop proposed three possible hydraulic engineering design strategies and evaluated them: First, to prevent flooding by increasing the elevation of the base. This strategy is relatively straightforward, but involves huge earthworks; Second, to establish a flood defense system, such as dikes, sluice, etc. and centralized flood discharge 
facilities, such as flood drainage channels and intercepting ditches, etc. This Strategy is more effective in a short period of time, but the centralized drainage facilities may lead to land subsidence; Third, to bring together the water conservancy and ecosystem to create a decentralized rainwater storage system to store, manage and reuse rainwater on site.

The first two strategies are rigid static water conservancy engineering methods, and often do not have the adaptability and learning ability in storm disasters. Once the future climate change makes the flood exceed the engineering design standards, the water inflow will still occur in this island. The last method is more flexible and sustainable, but it requires a certain amount of land. In summary, appropriate technical means should be selected in combination with the different situations of the site.

\subsection{Application of the Principles of Flexibility in Design}

The principles of flexibility in specific design is embodied in a smart and compact urban growth and a mixed-function block design. A mix-use zone is created within a walkable scale, and multiple zones are connected by constructing multiple levels of public space, so as to further enhance the interconnectivity and redundancy of urban resilience.

To achieve the resilient open space design of the above-mentioned combining urban planning, water conservancy engineering design and ecological landscape, and to meet the current development capacity, it is necessary to carry out appropriate high-density development in the constructed area of the central and eastern Pazhou, pre-planning spaces for green infrastructure. Combined with the walkable scale of "small blocks and dense road network", mix-use block design is proposed (Figure 8), according to the needs of development intensity of different regions. Besides, the urban public services are considered, to achieve a certain degree of the balance between occupation and residence in order to reduce carbon emissions. What's more, the adaptability of climate in south China is considered in the block design, such as the street interface in the form of an arcade, the ventilation openings and courtyards in the blocks, and the square design, and so on.

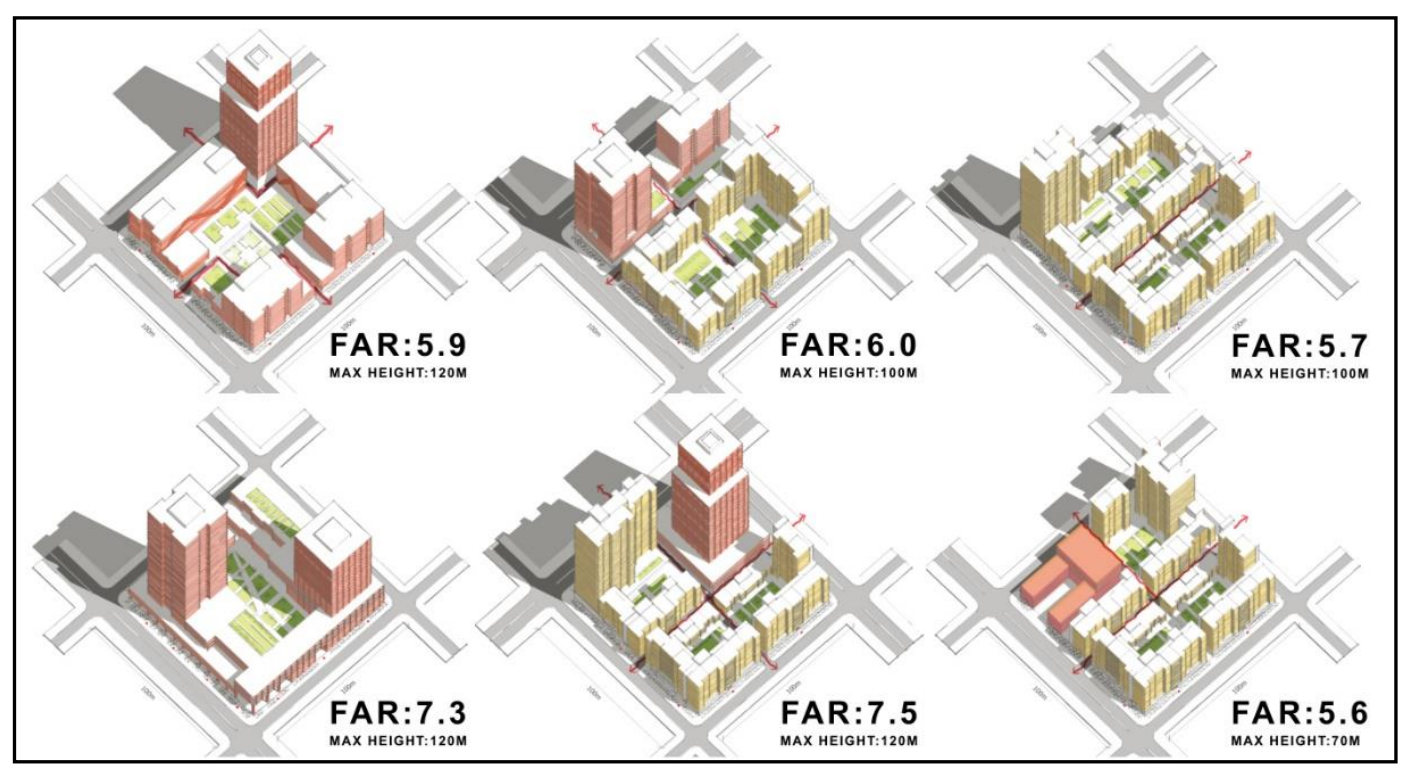

Figure 8 Block design of mix land use (Source: UCB-SCUT workshop) 


\section{Evaluation Feedback: Multi-program Quantitative Assessment of the Resilience}

Based on the initial formation of the urban design, we design a set of resilience indicators to evaluate the resilience of different urban design plans and feedback to the urban design stage. The purpose of the evaluation feedback is to introduce the theory of resilient city in the early stage of design, to form a comprehensive consideration of urban ecology, urban design and water conservancy. Through early scientific decision-making, the repeated planning and design modifications during the constructing phase are to be reduced, which may hopefully save time and resources.

\subsection{Time Series Model for Urban Resilience Assessment of Heavy Rainfall}

Not considering existing embankments, sluice gates and other water conservancy facilities and assuming that the urban drainage system runs smoothly and the water level of Pearl River remains constant $(7 \mathrm{~m})$, we construct a time-varying model for analyzing different rainfalls in Pazhou to simulate the impact of quantity of the rainfall on various urban systems. Input data includes different elevation areas for each design (Figure 9) and their corresponding land use type. The set scenarios are $50 \mathrm{~mm}, 100 \mathrm{~mm}, 200 \mathrm{~mm}$ precipitation, and the precipitation time is $3 \mathrm{~h}$. The quantified indicators of output include the height of the rise in stagnant water and the temporal changes in the various types of land that are submerged.

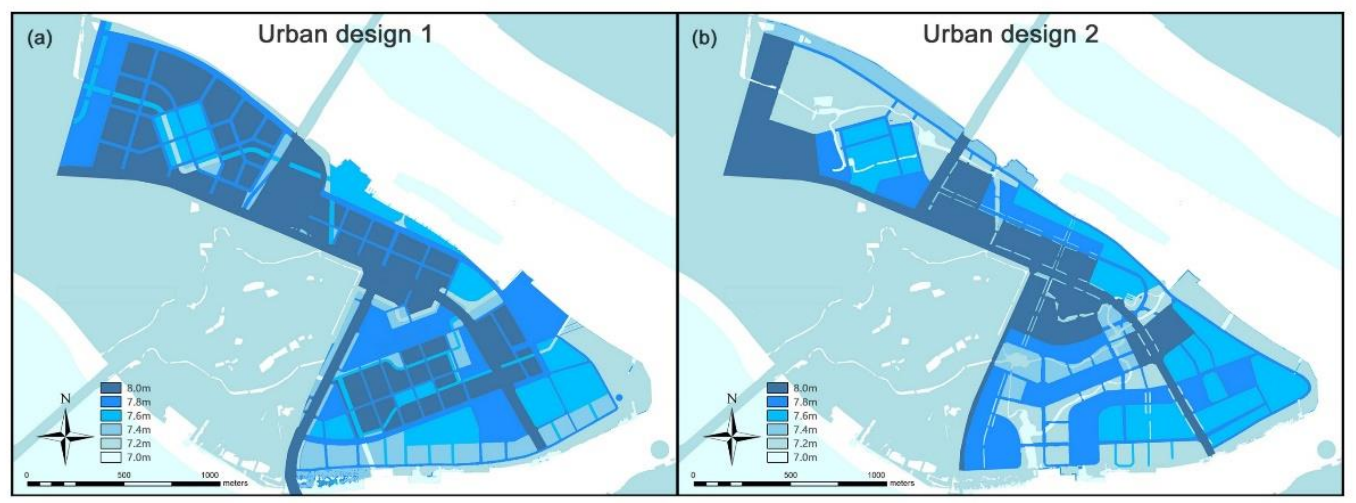

Figure 9 Elevation of two urban design (Source: UCB-SCUT workshop)

Figure 10 illustrates the temporal variation of the water surface height along the rainfall process in different scenarios. Overall, the water lever of urban design 1 has increased rapidly. The maximum height of the accumulated water is close to $0.7 \mathrm{~m}$. The speed of the stagnant water is also fast. The water level is maintained at $0.05 \mathrm{~m}$ within 9 hours after the precipitation. In urban design 2, the increase in the height of the accumulated water is relatively flat. The maximum height of the accumulated water is about $0.6 \mathrm{~m}$, but the speed of the whole water volume is also slower. It stays at about $0.1 \mathrm{~m}$ for a long time, so the time of water accumulation is longer. 


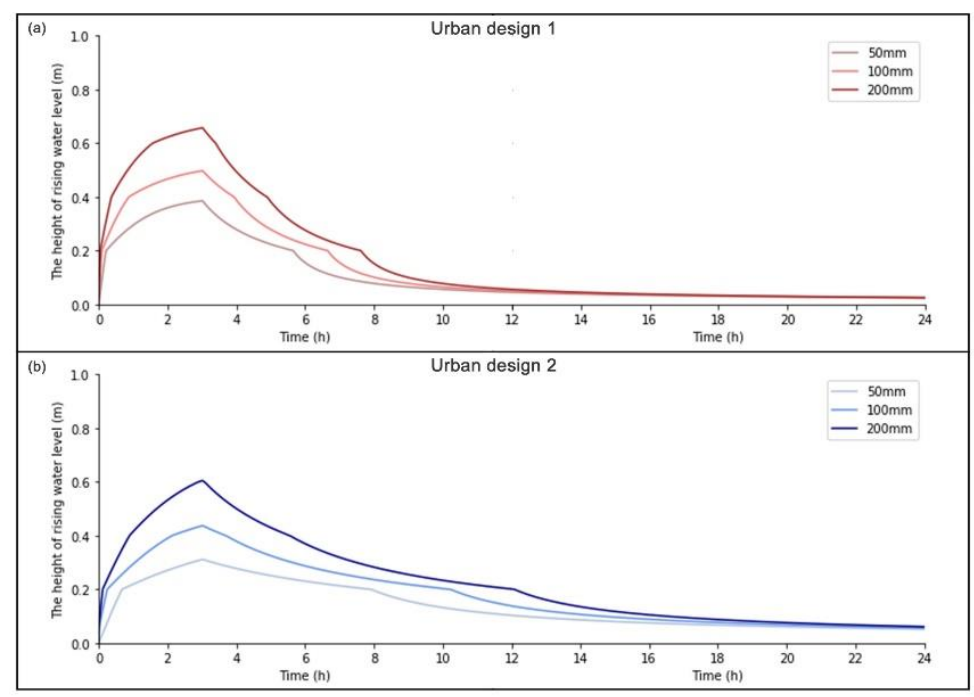

Figure 10 The temporal variation of height of rising water level in different scenarios in two urban design (by author)

Specifically, urban design 1 and 2 perform well in heavy rainfall facing $50 \mathrm{~mm}$ of rainfall, and the natural basement absorbs most of the precipitation and protects the urban system from precipitation. However, in the face of $100 \mathrm{~mm}$ heavy rainfall, there is a difference in the performance of the two. The natural basement of urban design 1 is difficult to absorb a sufficient amount of rainfall, but the urban infrastructure network is well protected because of the urban design, so precipitation directly affects commercial land on the layer of the urban settlement. Urban design 2 retains sufficient natural ecological land and green space, and the city has strong resilience. The difference in resilience between the two schemes is that: when facing with serious natural disasters, the overall recovery of urban design 1 is strong, but the capacity for disaster response is insufficient. About $10 \%$ of urban constructed land (commercial and residential land) is flooded. Although the recovery rate is slower in urban design 2, the disaster preparedness is sufficient. Only $4 \%$ of the urban land is inundated, and the late stage of disaster recovery mainly through the water system on the layer of the natural basement which does not affect the urban operation.

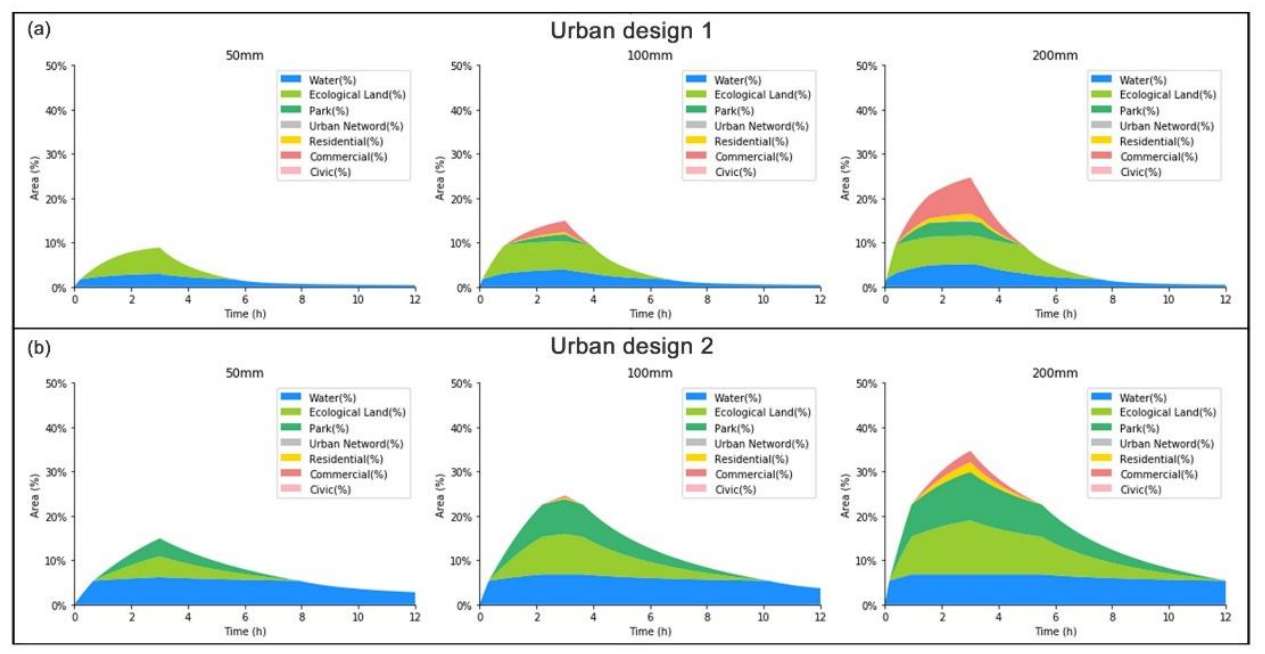

Figure 11 The temporal variation of area of various land use in different scenarios in two urban design (by author) 


\subsection{Feedbacks Based on the Results of the Assessment}

Based on the evaluation results, we put forward 3 feedbacks on the next stage of urban design to enhance urban resilience.

Appropriately increase the covering area of the natural basement and adjust its elevation to meet the urban water conservancy project implementation to achieve the 100-year construction standard, which can be continuously measured through the feedback model.

In residential and commercial areas that may be submerged, it is recommended that the ground floor be overhead and designed as a semi-public space to enhance the quality of the space and to cope with sudden precipitation.

The underground public space should be set up to consider the extent of flooding, and the underground public space entrance in the flooded area should be specially designed to protect the normal operation of the underground public space.

\section{Discussion}

\subsection{Interdisciplinary cooperation mode: integration of research, design and feedback}

The city is a complex giant system. Each city's challenges require multiple disciplines in collaboration to propose solutions. The natural disasters caused by climate change in cities also require urban planning, water conservancy projects, and ecological design to build an interdisciplinary platform. In this process, urban planning is responsible for formulating urban development frameworks from the perspective of urban systems and balancing the interests of each system. Ecological design is responsible for regulating the relationship between urban artificial systems and ecological natural systems, and adjusting the development framework to ensure sustainable urban growth. Urban design is responsible for shaping urban public spaces and urban blocks within the development framework and maintaining flexibility to face the future uncertainties. The water conservancy project is responsible for assessing and selecting appropriate engineering techniques to achieve sustainable goals. In this interdisciplinary exchange and cooperation process, it is indispensable to break through the traditional academic constraints of "architectural-planning-landscape" and to explore from a broader interdisciplinary field. It is the key to establish a cooperation mechanism between the urban study and other professions.

\subsection{Management and control platform: evaluation indicator, real-time monitoring and dynamic maintenance}

The evaluation feedback process can effectively adjust the design optimization direction and implementation direction, but the strength of the adjustment depends on the perfection of the evaluation index system. Through reflection on the evaluation index system in the design process, we understand that the above evaluation system is limited to the short-term impact on the urban system when natural disasters occur, and fails to show the strength of the urban reconstruction ability after encountering natural disasters. Moreover, the existing evaluation system is limited to a single target, and it fails to evaluate the impact of disasters on urban infrastructure (such as medical and municipal facilities) and urban population economic development. This is also part of the next work. 
It is important for a management and control platform to do real-time monitoring, regular assessment, and dynamic maintenance. In the planning and design phase, the platform can quantify the urban resilience of the design and guide to select excellent solutions. During the design implementation phase, the platform can supervise the implementation progress in real time, assess the urban resilience periodically, and compare design and implementation to find and correct the deviation. Besides, through the dynamic maintenance of the platform, the first-hand data of each system in the city can be obtained, which is beneficial to enriching the knowledge library of urban evolution and development, and further analyzing the law of urban evolution.

\section{Conclusion}

Resilient cities are not only the inevitable requirement of the development of the world city, especially the coastal cities, but also the practical need for the Greater Bay Area to realize leap-forward development. Based on the theory of resilient city, this paper proposed three resilient urban design principle and a research-design-feedback loop pattern and applied from the Greater Bay Area to urban zone-Pazhou. The practice process shows that the design research (the analysis of previous designs and patterns) and research-by-design (testing different possibilities for an area) both play an important role in resilience urban design. And these create a complete design closed-loop. The experience also points out the limitation of the evaluation index, suggests that the resilient city evaluation indicator needs to move from short-term to long-term and from a single goal to multiple goals, so as to improve the quality and efficiency of resilient cities.

(Designers and students participating in UCB-SCUT workshop include: Patrick Webb, Andrew Salmon, Mingxi Zhu, Lu Huai, Yuanjing Luo, Desong Shi, Preeti Srinivasan, Fanshu Li, Ziyu Cai, Eleni Oikonomaki, Sihan Sun, Dengyue Wang, Mingqi Xue. Thanks for your active participation)

\section{References}

Xiong, Liang; Steffen, Nijhuis(2019) Exploring spatial relationships in the Pearl River Delta, In Cities as Spatial and Social Networks, Springer: Cham.

Yang, Zhiwei; Chen, Yingbiao; Wu, Zhifeng; Zheng, Zihao (2018) "The Coupling between construction land expansion and urban heat island expansion in Guangdong-Hong Kong-Macao Greater Bay", Journal of Geo-information Science, Vol. 20 No. 11.

Xiong, Liang; Steffen, Nijhuis (2014) Urbanized deltas in transition, Techne Press.

Dai, Wei; Sun, Yimin; Han, Meyer; Bacchin, Taneha K (2019) “Delta spatial planning method based on system resilience", Urban Development Studies, Vol. 26 No. 01.

Wu, Qingzhou (2009) Research on flood control of ancient Chinese cities, China Architecture \& Building Press.

Wu, Qingzhou (2002) "A review of China's floods in the 20th century", Journal of Catastrophology. 
Dai, Wei; Sun, Yimin; Han, Meyer; Bacchin, Taneha K (2018) "Toward resilience planning: a study of delta planning based on international perspective", Urban Planning International, Vol. 33 No. 03.

Liu, Wei (2015) Study on the Relationship between Urban Canal-system of Ancient Guangzhou and City Development, South China University of Technology.

Li, Jiahao (2015) Research on Evolution and Dynamic Mechanism of Water, South China University of Technology.

Resilience Alliance (2007) Urban Resilience Research Prospectus, Australia: CSIRO.

Chen, Li; Zhu, Xigang; Sun, Jie (2017) "The Basic Concept, Mechanism and Planning Ideas of Resilient Cities", Modern Urban Research.

McHarg, lan L.; Lewis, Mumford (1969) Design with nature, New York: American Museum of Natural History

$\mathrm{Li}$, Guosheng; Li, Kuo (2013) "Integrated assessment on risk of storm surges in the central coastal area of Guangdong Province", Journal of Southwest University (Natural Science Edition), Vol. 35 No. 10. 